\title{
CELERIDADE PROCESSUAL E TECNOLOGIA: O USO DO APLICATIVO WHATSAPP COMO MECANISMO DE INTIMAÇÃO DE ATOS PROCESSUAIS
}

\author{
Claudia Karina Ladeia Batista ${ }^{1}$, Ivan Márcio Gitahy ${ }^{2}$, Raquel Rosan Christino Gitahy ${ }^{3}$ \\ ${ }^{1}$ Universidade Estadual de Mato Grosso do Sul - UEMS, curso de Direito, Dourados, MS. \\ ${ }^{2}$ Pontifícia Universidade Católica de São Paulo - PUC, curso de Direito, São Paulo, SP. \\ ${ }^{3}$ Universidade do Oeste Paulista - UNOESTE, curso de Direito, Presidente Prudente, SP. E-mail: \\ claudiabatistadv@hotmail.com
}

\section{RESUMO}

O presente trabalho tem por objetivo estudar as vantagens do emprego do whatsapp, um aplicativo utilizado para troca de mensagens por meio de conexão com a internet, como mecanismo de realização de intimação dos atos processuais. Por meio de pesquisa bibliográfica e documental e emprego do método dedutivo espera-se demonstrar que a celeridade processual e a instrumentalidade do processo hão de nortear a prática dos atos, de maneira que o apego demasiado às formas "tradicionais" de intimação podem obstacularizar a celeridade processual. Espera-se também apresentar as vantagens advindas da utilização do aplicativo, tais como a celeridade processual e a economia nas custas e despesas processuais.

Palavras-chave: celeridade processual; instrumentalidade do processo; tecnologia; Whatsapp; intimação.

\section{PROCESSUAL CELERY AND TECHNOLOGY: THE USE OF THE WHATSAPP APPLICATION AS A PROCEDURAL ACTS INITIATION MECHANISM}

\begin{abstract}
The purpose of this work is to study the advantages of using whatsapp, an application used for exchanging messages through an internet connection, as a mechanism for executing subpoenas of procedural acts. Through bibliographic and documentary research and the use of the deductive method, it is hoped to demonstrate that the procedural celerity and the instrumentality of the process will guide the practice of acts, so that too much attachment to the "traditional" forms of subpoena can obscure celerity Procedural law. It is also expected to present the advantages of using the application, such as procedural speed and savings in costs and procedural expenses.
\end{abstract}

Keywords: Procedural speed; Instrumentality of the process; technology; Whatsapp; Subpoena.

\section{INTRODUÇÃO}

O Direito Brasileiro confere ao processo um caráter publicista, cuja importância está ligada ao desempenho do monopólio estatal da jurisdição. Há que se considerar que no Brasil, há muito, o processo não é tido como um fim em si mesmo. Reveste-se, sim, "da característica ínsita de instrumento para promover justiça e paz social" (DINAMARCO, 2002, p.131). É justamente a partir dos princípios da instrumentalidade do processo e economia processual que se sustenta a presente pesquisa: o uso de novas tecnologias como meio de instrumentalizar a celeridade processual.

Em atendimento a tal celeridade o uso das tecnologias passou a ser regulamentado desde a lei $11.419 / 2006$ que trata da informatização do processo. Mais recentemente o Conselho Nacional de 
Justiça reconheceu a utilização do aplicativo Whatsapp como instrumento válido de intimação dos atos processuais (procedimento de controle administrativo no 0003251-94.2016.2.00.0000) ${ }^{1}$.

O Whatsapp, um aplicativo utilizado para troca de mensagens por meio de conexão com a internet, que está disponível para smartphones, iPhone, BlackBerry, Windows Phone, Android e Nokia, apresenta o ícone, conforme evidencia a figura 1.

FIGURA 1: Ícone do aplicativo WhatsApp

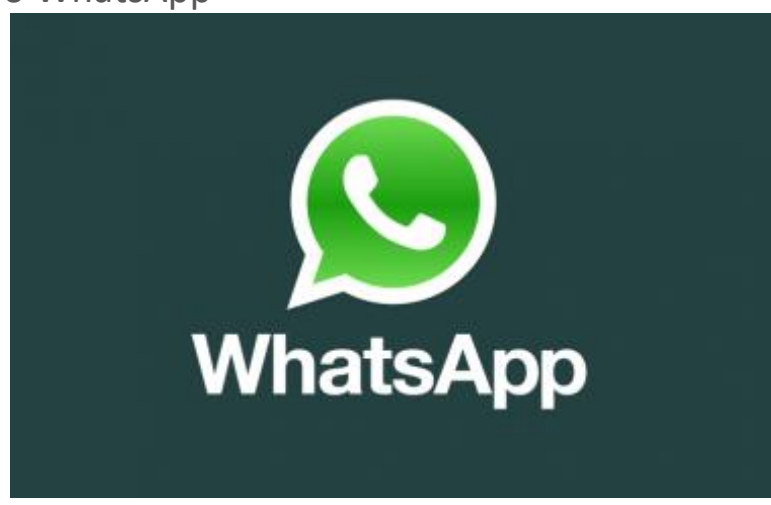

Na sociedade digital o uso das redes sociais, ou mais especificamente do WhatsAPP, é uma constante na vida dos cidadãos. O Brasil, segundo pesquisas do Mobile EcoSystem Forum (MEF), é o segundo país que mais usa o aplicativo. Desta maneira, considerando que o Direito acompanha a transformação social, é fundamental a reflexão a respeito das mudanças jurídicas, ou mais especificamente, processuais que tal ferramenta acarreta.

A partir das considerações acerca do processo como instrumento da jurisdição espera-se com o presente trabalho, ancorado nos princípios da instrumentalidade das formas e celeridade processual, estudar o emprego do aplicativo Whatsapp como instrumento apto à intimação válida das partes nos processos em trâmite.

\section{METODOLOGIA}

A presente pesquisa foi desenvolvida com o emprego do método dedutivo aplicado à pesquisa bibliográfica. Com a indução, método proposto pelos racionalistas, parte-se do geral para o particular, buscando referencial de embasamento em uma pesquisa bibliográfica, que segundo Gil (2008) é desenvolvida com base em material já elaborado, constituído principalmente de livros e artigos científicos.

\section{RESULTADOS}

Visando dirimir os conflitos de interesse por meio da apreciação juridisdicional, o processo passou a adotar mecanismos para a realização da justiça de maneira mais célere. O conteúdo e os objetivos do processo são mais preciosos que sua forma, de maneira que "não interessa uma ciência processual conceitualmente perfeita, mas que não consiga atingir os resultados a que se propõe" (BEDAQUE, 2003, p.17).

Assim sendo, em nome da celeridade processual, admite-se como eficaz o uso do aplicativo Whatsapp como instrumento válido à efetivação de intimação de atos processuais quando assim for de vontade das partes. A decisão do Conselho Nacional de Justiça autoriza o emprego do aplicativo como método de intimação facultativa dos atos processuais para as partes que assim manifestarem interesse.

\footnotetext{
${ }^{1}$ http://www.cnj.jus.br/noticias/cnj/85009-whatsapp-pode-ser-usado-para-intimacoes-judiciais Colloquium Socialis, Presidente Prudente, v. 01, n. Especial 2, Jul/Dez, 2017, p.258-262. DOI: 10.5747/cs.2017.v01.nesp2.s0145
} 
A celeridade e o custo zero do aplicativo em muito contribui para a prática de atos processuais mais céleres e, portanto, para a celeridade do processo como um todo. No mais, as garantias processuais não são violadas pela adoção consensual do instrumento como mecanismo válido de intimação.

\section{DISCUSSÃO}

Antes do Conselho Nacional de Justiça reconhecer a possibilidade de adoção do whatsapp como meio de intimação, o próprio CNJ, por meio da portaria 234, de 13 de junho de 2006, havia instituído o Diário de Justiça Eletrônico Nacional (DJEN). A referida portaria determina que enquanto não implantado o DJEN, as intimações seguiriam realizadas pelos Diários de Justiça dos estados.

Entretanto como tal plataforma ainda não foi implantada, alguns juízes, em nome da celeridade dos atos processuais, passaram a utilizar o whatsapp como instrumento de intimação. Após discussões e embates o CNJ chancelou a prática como válida ao decidir sobre a Portaria Conjunta Juizado Especial Cível e Criminal e OAB de Piracanjuba-GO, que instituiu a possibilidade de utilização do aplicativo Whatsapp como meio de realização de intimações caso as partes desejassem fazer uso da faculdade.

Acrescenta-se que o artigo 19 da Lei n. 9.099/95 (Juizados Especiais) prevê a utilização de "qualquer outro meio idôneo de comunicação", tendo a portaria considerada a intimação por whatsapp certificada nos autos como "visualizado" como prova de que a intimação ocorreu com sucesso.

Ademais, cumpre ressaltar que o artigo 20 da Lei n. 9.099/1995 prevê a condução dos processos sob "critérios da oralidade, simplicidade, informalidade, economia processual e celeridade[...]".

Luiz Guilherme Marinoni preceitua que: "É preciso compreender que o direito de ação não pode mais ser pensado como simples direito à sentença, mas sim como o direito a um modelo processual capaz de propiciar a tutela do direito afirmado em juízo"(MARINONI, 2006, p. 32). Ademais, é preciso propiciar a condução do processo de modo ágil, sem prejuízo do bom andamento processual e das garantias constitucionais visto que "a morosidade gera a descrença do povo na justiça. É óbvio que a morosidade processual estrangula os direitos do cidadão (MARINONI, 2000, p.33).

A efetividade da prestação jurisdicional guarda relação direta com a existência e finalidade do processo. Conforme preleciona Sérgio Cruz Arenhart (2000, p. 34) "[...] reconhecer um direito e não lhe dar a tutela adequada é o mesmo que não oferecer tutela ao direito em questão".

Kazuo Watanabe (1996) aponta

a necessidade de que a tutela jurisdicional seja adequada, ou seja, que o aprimoramento da técnica contribua para a efetividade na prestação jurisdicional posto que "Um dos dados elementares do princípio da proteção judiciária com semelhante alcance é a preordenação dos instrumentos capazes de promover a efetiva, adequada e tempestiva tutela dos direitos" (WATANABE, 1996, p. 20).

A constitucionalização do processo não faz do rito processual um fim em si. O processo há de ser um instrumento por meio do qual se concretizam direitos postos à apreciação judicial. É preciso, pois, que seja, acima de tudo, efetivo para tal finalidade. 
Ocorre que o tempo de tramitação dos processos é assunto fundamental, ganhando status constitucional e por força da Emenda no 45 de 23 de dezembro de 2004 introduziu na Carta Magna expressamente o direito ao processo célere ${ }^{2}$.

Ademais, como aponta Bedaque:

A duração do processo cognitivo ou executivo, muitas vezes exagerada ou inexplicável, representa obstáculo sério à plena satisfação do direito. Aqui nos deparamos com circunstâncias inerentes ao próprio sistema processual, às vezes ligadas a deficiências desse mesmo sistema, que acabam por constituir obstáculos à efetividade da tutela jurisdicional. É preciso buscar meios para afastá-los (BEDAQUE, 2006, p.21).

Fernando Horta Tavares (2008) faz considerações acerca do direito fundamental à razoável duração do processo, escrevendo

O novo princípio de direito fundamental da duração razoável do procedimento (e não do processo) e da celeridade de tramitação deve ser aplicado em estrita complementaridade com os demais princípios regentes da processualidade, isto é, isonomia, contraditório e ampla defesa, de modo a se dar uma interpretação sistêmica a este novo direito-garantia, também de índole fundamental, como os demais (TAVARES, 2008, p. 117)

A celeridade não pode colocar em risco o devido processo legal e a realização da justiça. Nesse sentido, por elucidativa, passa-se a transcrever os ensinamentos de Plínio Aroldo Gonçalves (2001):

A preocupação com o rápido andamento do processo, com a superação do estigma da morosidade da Justiça, que prejudica o próprio direito de acesso ao Judiciário, porque esse direito é também o direito à resposta do Estado ao jurisdicionado, é compartilhada hoje por toda a doutrina de Direito Processual Civil. As propostas de novas categorias e de novas vias que abreviem o momento da decisão são particularmente voltadas para a economia processual e a celeridade como predicados essenciais da decisão justa, sobretudo quando a natureza dos interesses em jogo exige que os ritos sejam simplificados. Contudo a economia e a celeridade do processo não são incompatíveis com as garantias das partes, e a garantia constitucional do contraditório não permite que ele seja violado em nome do rápido andamento do processo. A decisão não se qualifica como justa apenas pelo critério da rapidez, e se a justiça não se apresentar no processo, não poderá se apresentar, também, na sentença (GONÇALVES, 2001, p. 125).

\section{CONCLUSÃO}

A celeridade processual deve estar atrelada ao devido processo legal, a segurança jurídica, as garantias de ampla defesa e contraditório definido na Constituição Federal Brasileira. É preciso,

\footnotetext{
${ }^{2}$ Art. 50

LXXVIII - a todos, no âmbito judicial e administrativo, são assegurados a razoável duração do processo e os meios que garantam a celeridade de sua tramitação.

Colloquium Socialis, Presidente Prudente, v. 01, n. Especial 2, Jul/Dez, 2017, p.258-262. DOI: 10.5747/cs.2017.v01.nesp2.s0145
} 
pois, que o uso do aplicativo Whatsapp respeite as barreiras do devido processo legal e demais garantias constitucionais.

Conclui-se, portanto, que o uso do aplicativo Whatsapp, ancorado nos princípios da instrumentalidade das formas, celeridade processual e a busca da justiça, é bem vindo no sentido de alinhar a mudança social e a transformação do Direito.

\section{REFERÊNCIAS}

ARENHART, Sérgio Cruz. A tutela inibitória na vida privada. São Paulo: RT, 2000.

BEDAQUE, José Roberto dos Santos. Direito e Processo: influência do direito material sobre o processo. São Paulo: Malheiros. 2003.

Tutela cautelar e tutela antecipada: tutelas sumárias e de urgência (tentativa de sistematização). São Paulo: Malheiros, 2006.

BRASIL. LEI № 11.419, DE 19 DE DEZEMBRO DE 2006. Disponível em http://www.planalto.gov.br/ccivil_03/_ato2004-2006/2006/lei/l11419.htm. Acesso em 08 de ago. de 2017

BRASIL. LEI № 9.099, DE 26 DE SETEMBRO DE 1995.. Disponível em http://www.planalto.gov.br/ccivil_03/leis/L9099.htm. Acesso em 15 jul 2017

DINAMARCO, Cândido Rangel. A instrumentalidade do processo. São Paulo: Malheiros, 2002.

GIL, Antonio Carlos. Como elaborar projetos de pesquisa. 4. ed. São Paulo: Atlas, 2008.

GONÇALVES, Aroldo Plínio. Técnica processual e teoria do processo. Rio de Janeiro: Aide, 2001.

MARINONI, Luis Guilherme. Novas linhas do processo civil. 4.ed. São Paulo: Malheiros, 2000.

Tutela inibitória individual e coletiva. 2.ed. São Paulo: RT, 2006.

MOBILE ECOSYSTEM FORUM. Relatório de uso do Whatsapp. Disponível em <https://mobileecosystemforum.com/tag/whatsapp/> Acesso em 08 ago. de 2017

TAVARES, Fernando Horta. Tempo e Processo. In TAVARES, Fernando Horta (coord). Urgências de Tutela: processo cautelar e tutela antecipada. Reflexões sobre a efetividade do processo no Estado Democrático de Direito.Curitiba: Juruá, 2008.

WATANABE, Kazuo. Tutela antecipatória e tutela específica das obrigações de fazer e não fazer. In TEIXEIRA, Sálvio de Figueirado (coord) Reforma do Código de Processo Civil. São Paulo: Saraiva, 1996 